\title{
Novel injection concept: Line Bleeding Injection Pump (LBIP)
}

\author{
Mohamed Elashmawy ${ }^{1,2}$ \\ ${ }^{1}$ Mechanical Engineering Department, Engineering College, University of Hail, Hail, Saudi Arabia \\ ${ }^{2}$ Engineering Science Department, Faculty of Petroleum and Mining Engineering, Suez University, Suez, Egypt
}

Email address:

arafat_696@yahoo.com

To cite this article:

Mohamed Elashmawy. Novel Injection Concept: Line Bleeding Injection Pump (LBIP). Science Innovation.

Vol. 2, No. 4, 2014, pp. 37-42. doi: 10.11648/j.si.20140204.11

\begin{abstract}
Injection pumps are essential for water processes and water treatment. The main task of such pumps is to inject certain dose of chemicals in water streams. Diaphragm pump with electromagnetic core is the common pump type used. This type has many problems concerning its continuous needs of maintenance due to diaphragm changing and electromagnetic core corruption. The main target of the present work is to develop a novel design of injection pump that is more efficient and has less electrical and mechanical parts. The idea is to utilize the pressure inside the line and intensify it to produce pressure which is higher than the line pressure in order to inject chemicals in the same line. To satisfy such concept a certain amount of line water should be bleed out. The amount of bleed water should be more than the amount of chemical injected by a certain percentage. The amount of bleed water could be either recycled to the line itself by using a small centrifugal pump or drained out. The new injection pump is designed with simple variable displacement facility that covers a wide range of injection doses (10-500 Liters per day) and capable of injecting any line regardless of how high pressure it is. The novel injection concept provides a strong and new facility for injection pumps used for water production market. The new concept using simple design and normal materials can reduce the cost to very competitive price compared to other injection pump types. The new design requires no driving power except for the line pressure itself. This could be promising for renewable seawater desalination researches and plants in remote areas.
\end{abstract}

Keywords: Injection, Pump, Pressure Intensifier, Line Bleeding

\section{Introduction}

Drinking water is the most important element keeping us alive. Water is also essential for agriculture to satisfy our food needs and for many industrial applications. It is well known that the world natural fresh water resources are constant. The increase of population and fixed fresh water natural resources is a big challenge in the future. Water needs increases rapidly around the world; water desalination is the most common solution to satisfy drinking water needs especially for areas near by oceans and seas. The total nowadays world desalination market amount is around 70 million $\mathrm{m}^{3} /$ day and expected to reach 120 million $\mathrm{m}^{3} /$ day by 2020 . Even though desalination technologies are mature enough with increasing importance and exponential expansion, its environmental impact is not well known yet, many research efforts were made to develop water production technologies that provoke a lower environmental impact [1]. Therefore Renewable Energy desalination (RE/desalination) is becoming competitive at more places and different technologies; this makes it ready for challenge in this potential market [2].

Injection process is very essential for water treatment. The most widely used type is the diaphragm injection pump units. The main advantages of such pump types are its simplicity, precise and compact design, it is suitable for metering injection applications. The main problems with diaphragm pumps are its membrane which should be very flexible and at the same time should bear high stress and fatigue. The membrane is subjected to intensively cyclic fatigue and high stress at certain points which cause failure in its material within relatively short time period. The different behavior in pumping speed and ultimate pressure of rotational speed controlled diaphragm pumps in comparison to constant-speed pumps is related to the mechanical properties of the valves and gas dynamics [3]. 
In order to satisfy high pressure injection applications, piston pump unite is used. The main advantage of piston pumps is its high volumetric efficiency due to surface contact between piston and cylinder [4].

\subsection{Chemical Metering Pumps and Chemical Injection}

A metering pump is a pump used to pump chemicals at adjustable flow rates which are averaged over time. The delivery of fluids in precise adjustable flow rates is sometimes called metering. The term "metering pump" is based on the application or use rather than the exact kind of pump used. Many metering pumps are rated to be able to pump into a high discharge pressure, and are typically made to meter at flow rates which are continuous when averaged over time. Avoiding leakage at the packing or seal is accomplished by using diaphragm pumps for metering. Diaphragm pumps normally need for heavy-duty gear reducer system for superior performance. Hydraulically actuated diaphragm minimizes diaphragm fatigue. Built-in hydraulic relief valve protects the pump. Stroke rate easily automated using variable-speed drive.

Driving of the injection pump could be one of the following: (1) Hydraulically Actuated Metering Pumps, (2) Air/Gas Driven Chemical Injection Pumps, (3) Electric / Engine Driven Chemical Injection Pumps, and (4) Power Impeller Driven Chemical Injection Systems. Fig. 1A shows typical industrial diaphragm pump having flow range from 3.3 to $212 \mathrm{l} / \mathrm{h}$ and pressure range from 17.6 to $70 \mathrm{Kg} / \mathrm{cm}^{2}$ [5].

Chemical metering pump is a main part for many industrial applications such as: metering of additives in industrial water, water treatment in power plants, refineries, chemical industry, food industry and oil \& gas industry. LEWA-ecosmart metering pump was developed to meet intensive industrial applications, for example: a PVC pump end is used to allow metering pumps to be used for aggressive chemical including water treatment industry. Of course PVC end will reduce the maximum injection pressure and temperature of the pump. The limitation is up to 12 bar and $60{ }^{\circ} \mathrm{C}$, which is suitable for many applications. Stainless steel head is available for higher pressure and temperature applications [6].

Watson-Marlow pumps group recently introduces a new chemical metering pump (QDOS 60 model). This pump was designed to provide high accuracy with low costs for chemical metering applications such as large water treatment plants, fluid level monitoring, fluid recovery, line priming and intuitive flow calibration [7].

\subsection{Research Efforts Concerning Injection Pumps}

A study proposes a micro pump using PDMS diaphragm. The resulting deflection of the Polydimethylsiloxane PDMS diaphragm creates an acoustic impedance mismatch within the micro-channel, which results in a net flow. A deflection of $30 \mu \mathrm{m}$ is obtained by supplying the micro coil with an input current of $0.6 \mathrm{~A}$, and results in a flow rate of $1.5 \mu \mathrm{l} / \mathrm{sec}$ when the PDMS membrane is driven by an actuating frequency of $240 \mathrm{~Hz}$ [8].

Structure and operating principle of micro valve-less pump, were investigated theoretically and experimentally. The work provides useful reference for structure optimization selection of the driving diaphragm of micro valve-less pump [9].

Pneumatic diaphragm pumps are used widely in the national economy. A "weak" component of such pumps is the diaphragm, upon which depends on the duration of continuous operation of the pump [10].

In a study of developing a fully magnetic resonance-compatible withdraw/infuse syringe pump. The injector can be programed for variable injection volumes and rates to permit the rapid and reproducible injection of hyperpolarized material without human intervention [11].

Ultrafast spin dynamics of excitons is studied in a double quantum well composed of $\mathrm{Cd}_{0.92} \mathrm{Mn}_{0.08} \mathrm{Te}$ and CdTe wells with a $\mathrm{Cd}_{0.80} \mathrm{Mg}_{0.20}$ Te tunnel barrier, in magnetic fields, by pump-and-probe absorption spectroscopy [12].

A novel inexpensive $0.6 \mathrm{MPa}$ flow system based on a low-cost diaphragm pump has been developed [13].

For higher pressures injection, piston injection pump units should be used [14].

\section{Principal of Novel Injection Pump}

The novel injection pump design is given the abbreviation LBIP, "Line Bleeding Injection Pump". Fig. 1 shows a schematic diagram for suggested LBIP design connected to the line.

The action of hydraulic line pressure is used to inject the same line with required injection doses. The idea is to magnify the line pressure using intensifier to produce higher pressure in the other piston end to inject the chemicals in the same line. To satisfy this principal the line water charged to the intensifier should be drained during the suction stroke. A 3-way control valve is used to accomplish this task. The suction stroke is only driven by a spring action. Two non-return valves are used for suction and delivery injection ports as shown in Fig. 1. The bleed water could be either pumped back to the line or drained back to the sea.

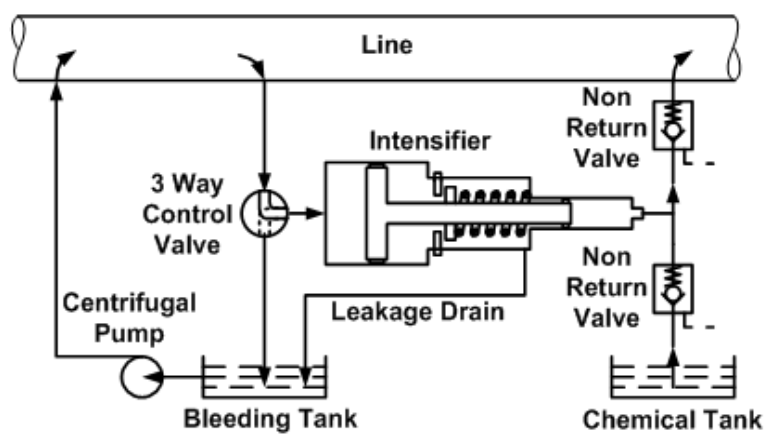

Figure 1. Schematic diagram for suggested novel LBIP design.

\subsection{Proposed LBIP Design}

Fig. 2 shows detailed 2D-CAD for the proposed LBIP. 
The numbers stated in Fig. 2 is defined in Table 1. The new design can cover a wide range of discharge. The variable displacement mechanism $(13,14$ and 15) satisfies 8 different displacement modes. By engaging cyclic speed of the control valve (4) in the game, LBIP will cover a wide range of injection flow (10-500 liter/day).

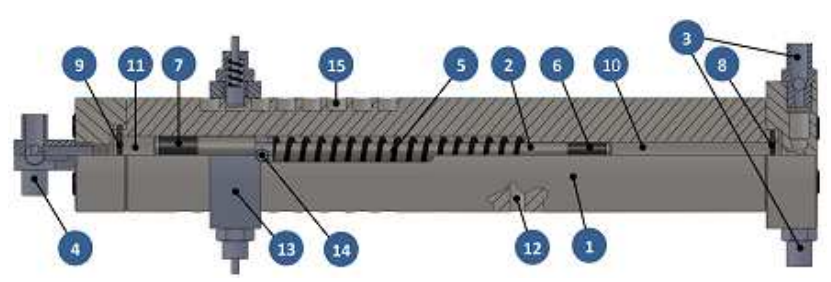

Figure 2. 2-D CAD sectional view for suggested LBIP design.

\subsubsection{LBIP Theory of Design}

Solonoid with electro magnetic control system could be used to control the cyclic speed of the 3-way control valve (4). Servo motor is an alternative control system for the valve. 3-way control valve satisfies only two modes as follows:

Mode1: The valve connects line flow to bleeding cylinder (11); and closes the way to the bleeding tank, see Fig. 1.

Mode2: The valve connects bleeding cylinder (11) to bleeding tank; and closes the way to the line flow.

For mode1, the piston end in the bleeding cylinder side (11) is subjected to the line pressure $\left(P_{L}\right)$ which applies a force $F\left(F=P_{L} \times A_{L}\right)$. The other piston end will exerts the same force to the injection cylinder (10) whcih applies a pressure of $\left(P_{I}=F / A_{I}\right)$. Where $P_{L}$ :Line Pressure, $P_{I}$ : Injection pressure, $F$ : Piston force, $A_{L}:$ Line side cross sectional area, $A_{I}$ : Injection side cross sectional area.

During delivery stroke suction none-return valve (3) is automatically closed and delivery one is automatically open. The pressure inside injection cylinder is equal to $F_{L} \times$ $\left(A_{L} / A_{I}\right)$.

At the end of delivery stroke the piston will stop and keep stopping until the control valve swiches to mode2. In mode2 the bleeding cylinder (11) will be opend to the bleeding tank while the line port is closed. The pressure inside bleeding cylinder will be released and subjected to the atmospheric pressure. The piston will travel back under spring action (5). The non-return valves (3) will automatically reverse its positions to open the injection room (10) to the suction chemical tank. At the end of piston back travel the injection cylinder will be filled with chemicals that required to be injected in the line. The piston will wait until mode1 coms again. The speed of switching between mode1 and 2 will control the descharge of the LBIP. At the same time a piston regulator pin (14) will stop the regulator mode set (13) at one position of the 8 casing regulator holes (15). This will satisfy an additional very wide control of pump flow range, see Figs. $3 \& 4$ and table 2 .

At a certain position of part (13) the piston regulator pin (14) will stop during its suction jurny stopping the suction stroke at that level and wait till the control valve switches to mode 1 again.
Of coarse during the suction strock in case of mode 2 the line water filled inside bleeding cylinder will bleed out to the bleeding tank. The bleeding tank will be filled with line fluid. At certain level it could be either pumped back to the line or drained back to the unit intake source.

All parts of the LBIP desig were designed using 3D-CAD SolidWorks. A 1.5 ratio of piston diameters was selected to satisfy area ratio of 2.25 . Increasing area ration will certainly satisfy a strong and fast injection action, but this will be at an expense of line flow bleeding amount. The selected ratios is just a base to start from. Area ratio is very important parameter that should be further investigated cairfully in the future work.

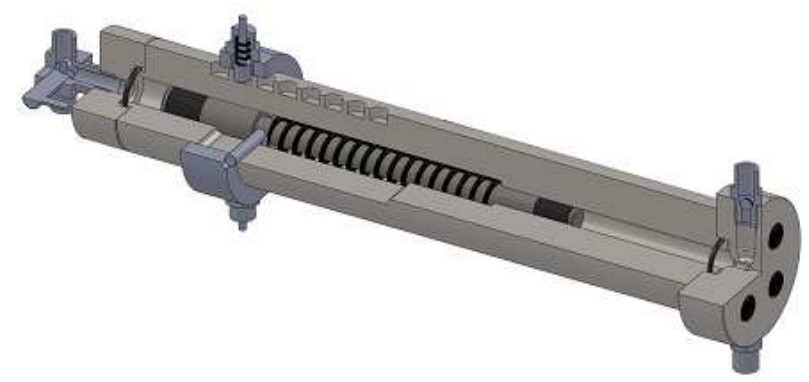

Figure 3. 3-D CAD for suggested LBIP design, $1 / 4$ Section.

Table 1. Definitions of numbering stated on Fig. 2.

\begin{tabular}{ll}
\hline Item No & Definition \\
\hline 1 & Casing \\
2 & Piston \\
3 & Suction and delivery non return valves \\
4 & 3way control valve \\
5 & Suction action spring \\
6 & Injection piston seal \\
7 & Bleeding piston seal \\
8 & Injection housing O-Ring seal \\
9 & Bleeding housing O-Ring seal \\
10 & Injection side cylinder \\
11 & Bleeding side cylinder \\
12 & Drain hole \\
13 & Regulator mode set \\
14 & Piston regulator pin \\
15 & Casing regulator holes \\
\hline
\end{tabular}

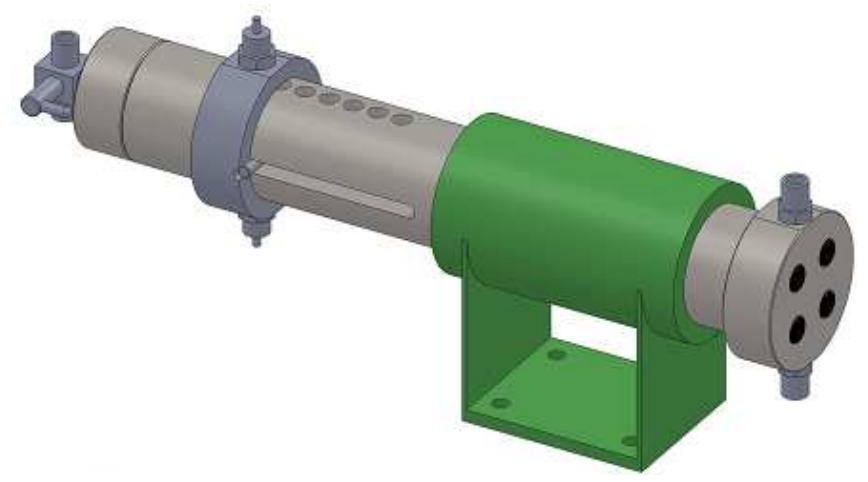

Figure 4. LBIP 3-D CAD assembly, pump complete outlook.

Fig. 4 shows a complete isometric outside view of the LBIP showing the pump holding frame. 
Table 2. Nominal discharge of LBIP for the 8 regulator modes based on regulation valve cyclic speed of 30 cycle /min.

\begin{tabular}{lllll}
\hline Discharge, I/day & $\begin{array}{l}\boldsymbol{\Delta} \mathbf{V}, \\
\mathbf{m l} / \text { Stroke }\end{array}$ & $\boldsymbol{\Delta X}, \mathbf{C m}$ & $\mathbf{S}, \mathbf{m m}$ & $\begin{array}{l}\text { Regulator } \\
\text { Mode }\end{array}$ \\
\hline 16.965 & 0.393 & 0.5 & 6 & RM 1 \\
50.894 & 1.178 & 1.5 & 16 & RM 2 \\
84.823 & 1.963 & 2.5 & 26 & RM 3 \\
118.752 & 2.749 & 3.5 & 36 & RM 4 \\
152.681 & 3.534 & 4.5 & 46 & RM 5 \\
186.611 & 4.320 & 5.5 & 56 & RM 6 \\
220.540 & 5.105 & 6.5 & 66 & RM 7 \\
254.469 & 5.890 & 7.5 & 76 & RM 8 \\
\hline
\end{tabular}

\section{Results and Discussion}

The novel injection concept provides an easy way of variable displacement control through a simple regulation facility by holing the piston during its suction stroke at 8 different positions (regulation modes, RM1-RM8), Fig. 5. Each position satisfies certain amount of suction dose.

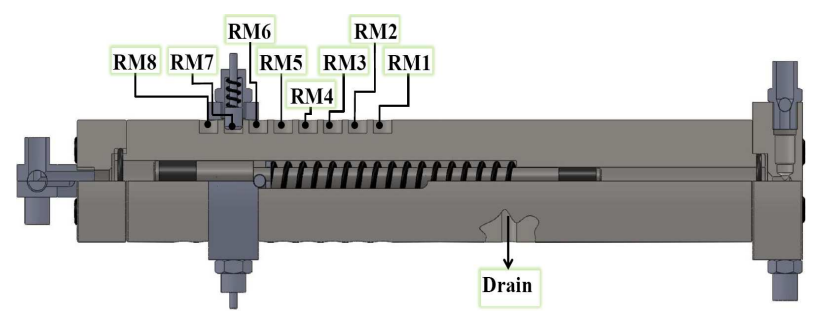

Figure 5. Half sectional view of LBIP assembly shows the pump 8-regulation modes, current mode is RM7.

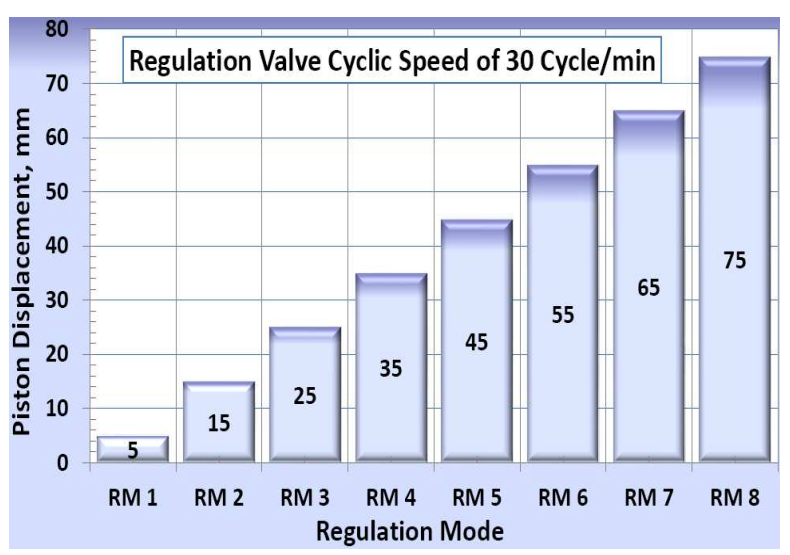

Figure 6. Regulation mode vs. piston displacement.

Fig. 6 shows piston displacement of the LBIP versus the 8 regulation modes. The regulation facility enables the pump to cover wide range of displacement from $5 \mathrm{~mm}(0.4$ $\mathrm{ml})$ to $75 \mathrm{~mm}(5.9 \mathrm{ml})$.

Each regulation mode position from RM1 to RM8 satisfies a certain amount of pump discharge depending on the regulation valve cyclic speed. Fig. 7 shows the pump curves of nominal pump discharge as a function of valve cyclic speed for the 8 different regulation modes. The two control facilities (regulation mode and valve speed) provide a wide range of injection capacity (10-500 liter/day).

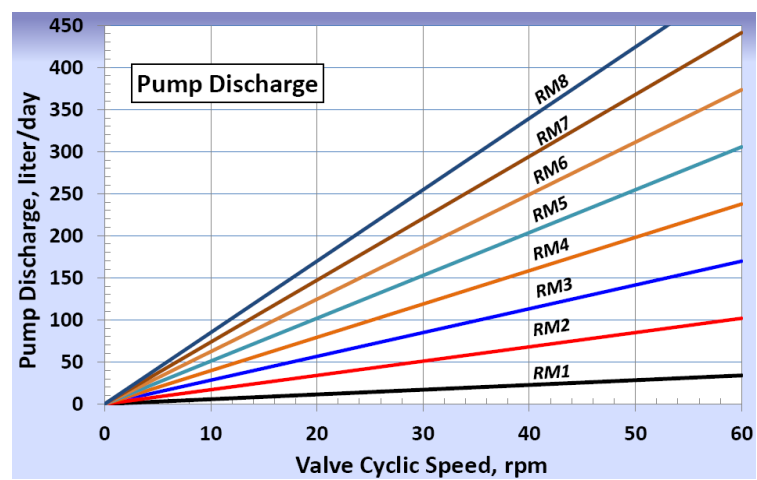

Figure 7. Effect of valve cyclic speed on pump nominal discharge at various regulation modes.

Each point of pump discharge mode is accompanied by certain amount of line bleeding. This amount is depending on the piston area ratio ( 2.25 for the present design).

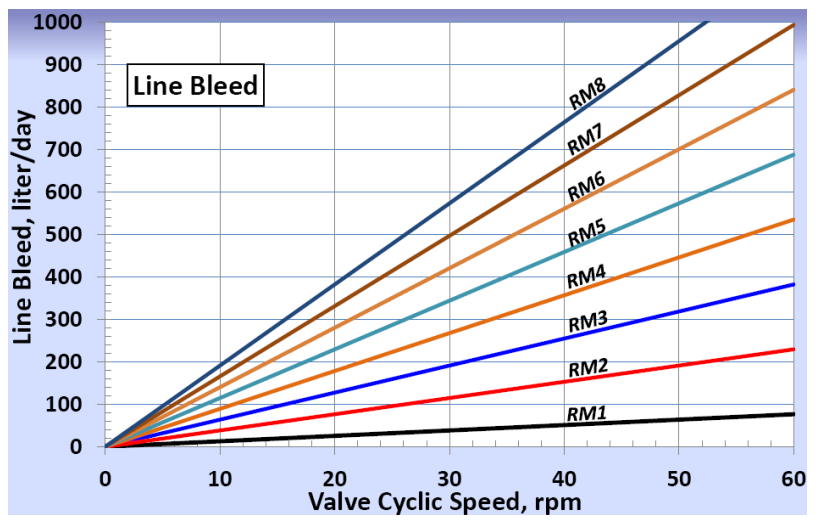

Figure 8. Effect of valve cyclic speed on line nominal bleed at various regulation modes.

Fig. 8 shows the amount of line bleeding for different pump regulation modes and valve cyclic speed.

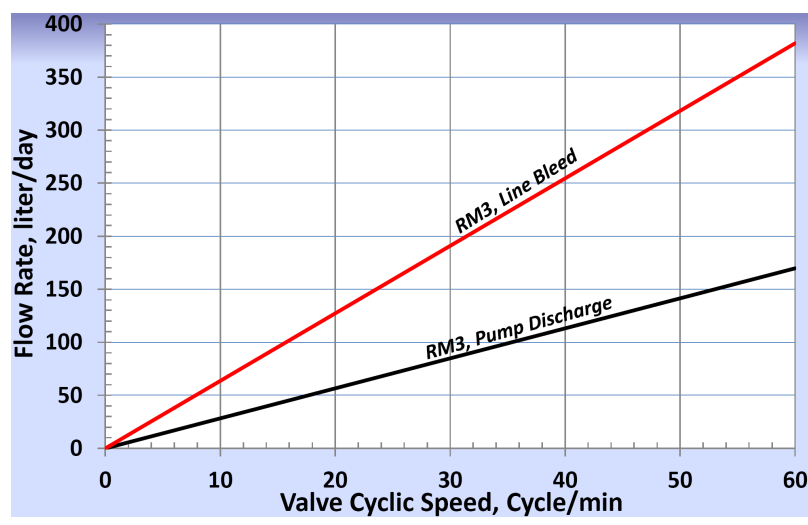

Figure 9. Effect of valve cyclic speed on pump nominal discharge and line nominal bleed at $R M 3$ regulation mode.

Fig. 9 show a comparison for the pump bleed with the pump discharge. Increasing the area ratio guarantee enough force to drive the pump piston at the expense of increasing the amount of pump bleed. This parameter should be further optimized through experimental investigations. The bleed fluid (almost water) could be easily pumped back to the line after certain 
period using normal pumps like centrifugal pumps or piston pumps for lines with relatively high pressure.

\section{Conclusion}

3-D CAD shows a feasibility of the proposed LBIP design principle. The novel design provides simple and wide control range of pump injection dosing. The new concept satisfies a strong facility for injection pumps used in the water production market. LBIP covers a wide range of injection flow (10-500 liter/day) using simple control facility. The simple design and materials used for LBIP could reduce its cost to very competitive price compared to conventional types available in the market. The new concept using simple design that is flexible to use different materials according to desired injection application. For example PVC materials could be used for aggressive chemicals with low pressures and temperature applications while proper metal materials should be used for high pressures and temperatures applications.

The new design requires no driving power except for the line pressure itself. This could be promising for renewable seawater desalination researches and plants in remote areas.

The novel LBIP design needs to be realized and subjected to the real situation. The performance of the new concept and its added value to the injection pump market should be measured. Some important parameters should be further carefully investigated; like piston ends area ratio, piston injection end diameter, driving and controlling facility to the 3-way control valve.

\section{Acknowledgments}

Acknowledgments to Deanship of Scientific Research, University of Hail, Saudi Arabia for funding and supporting this work, project code (E8 ME, $1^{\text {st }}$ round).

\section{Nomenclature}

$\begin{array}{ll}\text { LBIP } & \text { Line Bleeding Injection Pump } \\ \text { RE } & \text { Renewable Energy } \\ \text { PTFE } & \text { Polytetrafluoroethylene } \\ \text { PVC } & \text { Polyvinyl chloride } \\ \text { PDMS } & \text { Polydimethylsiloxane } \\ \text { RM } & \text { Regulator Mode } \\ P_{L} & \text { Line Pressure } \\ P_{I} & \text { Injection pressure } \\ F & \text { Piston force } \\ A_{L} & \text { Line side cross sectional area } \\ A_{I} & \text { Injection side cross sectional area } \\ \Delta X & \text { Piston displacement, cm } \\ \Delta V & \text { Volume displacement, ml/stroke } \\ Q & \text { Pump discharge, litre/day }\end{array}$

\section{Annex A}

\section{Typical Industrial Injection Pumps}

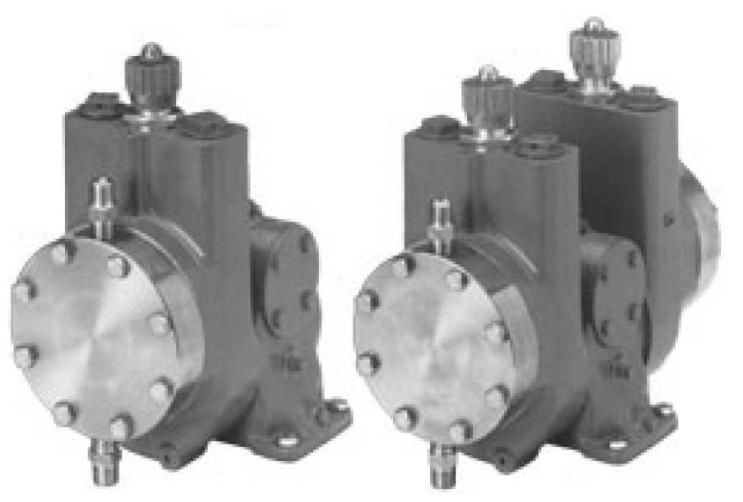

Figure 1A. Typical diaphragm pump [Source: McFarland-Tritan, LLC].

Fig. 1A shows a typical industrial diaphragm pump, the materials of construction: Diaphragm: PTFE, Liquid End: 316 Stainless Steel; PVC; Carpenter Alloy 20; Hastelloy-C. Flow rate varies from 3.26 up to $212 \mathrm{l} / \mathrm{h}$ and pressure from 17.6 to $70.3 \mathrm{Kg} / \mathrm{cm}^{2}$. For higher pressures injection, piston injection pump units should be used.

\section{References}

[1] R. Gemma Raluy, et al., "Life cycle assessment of water production technologies Part1: Life cycle assessment of different commercial desalination technologies (MSF, MED, RO)," Int. J LCA 10 (4), pp. 285-293, 2005.

[2] A. Cipollina, et al. (eds.)., "Sea water desalination, green technology and technology," Springer-verlag, Berlin Heidelberg, pp. 274-271, 2009.

[3] R. Lachenmann, and J. Dirscherl, "Advanced performance of small diaphragm vacuum pumps through the use of mechatronics," Applied physics A-Material Science \& Processing, Germany 78, pp. 671-673, 2004.

[4] H. Murrenhoff, "Grundlagen der fluidtechnik teil 1: Hyraulik. Umdruck zur Vorlesung," Shaker Verlag GmbH, Germany, 2005.

[5] http://mcfarlandpump.com/macj5.htm

[6] "Product news," WORLD PUMPS, February 2012.

[7] “Product news," WORLD PUMPS, September 2014.

[8] C. Y. Lee, et al., "A MEMS-based impedance pump based on a magnetic diaphragm," ICBME 2008, Proceedings 23, pp. 794-798, 2009

[9] X. Hai-bo, et al., "Effects of structural parameters and rigidity of driving diaphragm on flow characteristics of micro valveless pump," Journal of Zhejiang University SCIENCE V.4, No. 1, pp. 53-57, 2003.

[10] V. A. Kurteev, "Diaphragms for pneumatic pumps," Chemical and Petroleum Engineering, Vol. 47, Nos 7-8, pp. 550-556, 2011. 
[11] S. Reynolds, "Fully MR-compatible syringe pump for the controllable injection of hyperpolarized substrate in animals," Springer Verlag, Applied Magnetic Resonance, 2012.

[12] K. Nishibayashi, "Pump-Probe Spectroscopy of Exciton Spin Injection Process in Diluted Magnetic Quantum Wells," Journal of Superconductivity: Incorporation Novel Magnetism, Vol. 18, No. 3, pp. 399-404, 2005.
[13] A. Ratka, and H. Berndt, "A novel analytical low-cost flow system based on a $0.6 \mathrm{MPa}$ (84 psi) diaphragm pump applied to on-line trace pre-concentration in flame AAS and ICP-OES,” Springer-Verlag, pp. 275-280, 2002.

[14] Calder Company, UK, www.calder.co.uk, 2013 